\title{
PENGARUH KEMIRINGAN STRAIGHT BLADE TERHADAP PENINGKATAN KEMAMPUAN SELF-STARTING TURBIN HIDROKINETIK ARTICULATING H-ROTOR
}

\author{
Desy Rianti ${ }^{1}$, Dwi Anung Nindito ${ }^{2}$, Raden Haryo Saputra ${ }^{3}$ \\ Universitas Palangka Raya, Indonesia \\ DOI: http://dx.doi.org/10.26623/teknika.v14i2.kodeartikel
}

\section{Info Artikel}

Sejarah Artikel:

Disubmit 31-08-2021

Publish 30-12-2021

\section{Keywords:}

articulating h-rotor; hydrokinetic; self-starting; flow velocity distribution

\begin{abstract}
Abstrak
Articulating H-Rotor merupakan pengembangan turbin H-Darrieus yang memiliki straight blade miring dengan tujuan memperbaiki self-starting yang buruk karena dominasi gaya angkat (lift). Seberapa besar pengaruh kemiringan straight blade terhadap performa turbin menjadi penting diteliti. Studi ini bertujuan mengetahui pengaruh kemiringan straight blade turbin Articulating H-Rotor untuk mendongkrak kemampuan self-starting. Metode uji eksperimental turbin hidrokinetik dilakukan di saluran air (flume) menggunakan 3 blade profil NACA0018 dengan memvariasi kemiringan sudut $0^{\circ}$ (blade vertikal), $30^{\circ}$ (blade mengembang) dan $-30^{\circ}$ (blade menguncup). Hasil yang diperoleh menunjukkan bahwa turbin hidrokinetik Articulating H-Rotor dengan kemiringan blade $0^{\circ}$ memiliki nilai RPM yang lebih besar dan lebih dominan bekerja dengan gaya lift. Turbin hidrokinetik Articulating H-Rotor dengan kemiringan blade $30^{\circ}$ menghasilkan torsi yang lebih tinggi dan menambah gaya seret (drag) sehingga meningkatkan self-starting untuk berotasi. Bentuk luas bidang tangkap turbin dengan kemiringan blade $30^{\circ}$ lebih mampu merespon energi kinetik yang ditimbulkan dari profil distribusi kecepatan aliran air. Hasil studi ini bisa memberi kontribusi dalam mendesain turbin H-Darrieus blade miring.
\end{abstract}

\section{Abstract}

The Articulating of H-Rotor is a development of the turbine from H-Darrieus which has a straight blade tilted with the aim of correcting poor self-starting due to the dominance of lift force. How likely is the influence of straight blade slope on turbine performance and it is important to be examined. This article describes the effect of straight blade slope of the Articulating H-Rotor turbine to increase the self-starting ability. Hydrokinetic turbine experimental test method was carried out in a water channel (flume) using 3 NACA 0018 profile blades with varying inclination angles of $0^{\circ}$ (vertical blade), $30^{\circ}$ (inflated blade) and $-30^{\circ}$ (cupped blade). The result indicated that the Articulating $H$ Rotor hydrokinetic turbine with a blade slope of $0^{\circ}$ had a larger $R P M$ value and it was more dominant in working with lift force. The Articulating H-Rotor hydrokinetic turbine with a blade tilted of $30^{\circ}$ provides higher torque and increases drag, increasing self-starting for rotation. The shape of the turbine frontal area with a blade slope of $30^{\circ}$ was better able to respond the kinetic energy that raised from the flow velocity distribution profile of the water flow. The results of this study can be used as a guide to the design of the tilted blade H-Darrieus turbine. 


\section{PENDAHULUAN}

Indonesia merupakan negara kepulauan yang berpotensi besar untuk menggunakan pembangkit listrik tenaga mikrohidro karena memiliki banyak sungai serta curah hujan yang tinggi (Erinofiardi, dkk. 2017; Edy Susilo, dkk. 2017). Hidrokinetik merupakan salah satu konversi energi dari aliran air seperti sungai, saluran buatan dan arus laut (Khan, dkk. 2009; Yohanes, dkk. 2014). Pemanfaatan energi hidrokinetik dilakukan oleh turbin low head berjenis hidrokinetik yang memiliki kriteria desain dengan portabilitas baik, biaya murah, bertahan lama, dengan perawatan yang mudah (Tanier-Gesner, dkk. 2014) serta dapat digunakan sebagai PLTA yang berbasis teknologi lokal dengan skala kecil (Nindito \& Kamiana, 2010). Turbin hidrokinetik memiliki tiga tipe yakni Horizontal Axis Turbine (HAT), Cross Flow Turbine dan Vertical Axis Turbine (VAT). Jenis turbin hidrokinetik tipe HAT, seperti Archimedes Spiral dengan penambahan ekor pengarah dan truncated cone (Pratama, dkk. 2020). Jenis turbin tipe VAT, seperti Darrieus, Spinning Top Daerrieus (Wardani, dkk. 2020), H-Darrieus, Turbin DNA yang merupakan pengembangan turbin Gorlov (Antomo, dkk. 2020), Savonius dan turbin Tornado Savonius (Yudistira, dkk. 2021a) yang terinspirasi dari bentuk profil kecepatan air (Nindito, dkk. 2008). H-Darrieus merupakan jenis turbin dengan bilah lurus (straight blade) yang kemudian berkembang menjadi turbin Articulating, Tilted dan Helical H-rotors (Tjiu, dkk. 2015).

Turbin H-Darrieus sumbu vertikal bekerja dengan menggunakan gaya angkat (lift) (ed-Dîn Fertahi, dkk. 2018), tidak seperti turbin Savonius yang dominan menggunakan gaya seret (drag) (Yudistira, dkk. 2021b). Pembentukan koefisien lift dan drag tergantung bilangan Reynolds dan sudut serang pada turbin (Patel, dkk. 2017). Turbin H-Darrieus memiliki kelemahan berupa self-starting yang buruk. Self-starting merupakan kemampuan turbin berakselerasi dari diam ke kondisi Tip Speed Ratio secara kontinyu di jalur rotasi (Worasinchai, dkk. 2016). Turbin memiliki kemampuan self-starting jika dapat berakselerasi ke kecepatan gerak bebasnya sehingga dapat mengikuti kurva torsi (atau daya) yang sesuai pada kondisi kecepatan aliran tetap (Bianchini, dkk. 2016). Upaya untuk meningkatkan self-starting turbin Darrieus telah dilakukan oleh beberapa peneliti. Scungio, dkk. (2016) menambah blade turbin konvensional sehingga menjadi dua airfoil di tiap pasangan bilahnya. Octauria, dkk. (2021) dan Ichsan, dkk. (2021) menambahkan Omni Directional Guide Vanes (ODGV) untuk memusatkan arah aliran menuju bilah turbin sehingga self-starting meningkat dengan mekanisme pengaliran merujuk pada studi Shimokawa, dkk. (2012). Profil blade dan desain turbin yang tepat terbukti mampu menambah gaya seret sehingga meningkatkan kemampuan self-starting walaupun tanpa komponen tambahan (Batista, dkk. 2015). Profil blade menggunakan airfoil NACA0018 memiliki karakteristik mampu melakukan self-starting (Asr, dkk. 2016) dan mengurangi torque ripples pada turbin (Nakashima, dkk. 2016). Semakin tebal airfoil yang digunakan maka semakin tinggi koefisien drag, sehingga memberi karakteristik self-starting yang lebih baik pula (Arab, dkk. 2017). Performa turbin hidrokinetik ditunjukkan oleh parameter Coefficient of Power (Cp) dan nilai Tip Speed Ratio (TSR). Dai, dkk. (2011) menguji model pada turbin hidrokinetik H-Darrieus dengan menggunakan NACA0025 dan $\sigma=0,98$, menghasilkan TSR $=1,94$ dan Cp maks $=30,4 \%$. Brusca, dkk. (2015) menggunakan NACA0012, dengan 5 blade dan $\sigma=0,3$ menghasilkan nilai TSR mendekati 3 dan Cp di antara 0,4 - 0,45. Gorle, dkk. (2016) menggunakan NACA0015 dengan 4 blade, kecepatan $\left(\mathrm{V}_{0}\right)=1-3 \mathrm{~m} / \mathrm{s}$, menghasilkan TSR $=1,5-3,5$ dan $\mathrm{Cp}=0,05-0,35$. Wang, dkk. (2016) menggunakan NACA0018 dengan 3 blade, saat kecepatan aliran $2 \mathrm{~m} / \mathrm{s}$ menghasilkan TSR $=2,2$. Kirke \& Lazauskas (2011) menggunakan NACA0018 dengan 3 bilah, $\sigma=0,3$ menghasilkan $\mathrm{Cp}=0-0,5$ dan TSR $=0-4,5$. Self-starting untuk meningkatkan performa turbin H-Darrieus di studi terdahulu dilakukan dengan menambah blade, mengkombinasi rotor (turbin hibrid), merubah bentuk profil dan ukuran blade serta menambah pengarah aliran.

Articulating H-Rotor seperti yang ditunjukkan pada Gambar 1a merupakan pengembangan turbin H-Darrieus berjenis VAT dengan straight blade miring yang diharapkan mampu merespon gaya fluida yang mengenai airfoil turbin (Bruce, dkk. 2010) seperti yang tertera pada Gambar 1b. Namun seberapa besar kemiringan sudut straight blade yang optimal dari turbin Articulating H-Rotor untuk 
merespon gaya kinetik aliran air hingga kini belum pernah diteliti. Pengaruh sudut kemiringan straight blade pada turbin hidrokinetik Articulating H-Rotor menjadi salah satu solusi untuk meninjau kemampuan self-starting yang optimal pada turbin ini. Peningkatan self-starting turbin Articulating $\mathrm{H}$ Rotor saat berotasi diharapkan dapat menambah performa turbin menjadi lebih baik.

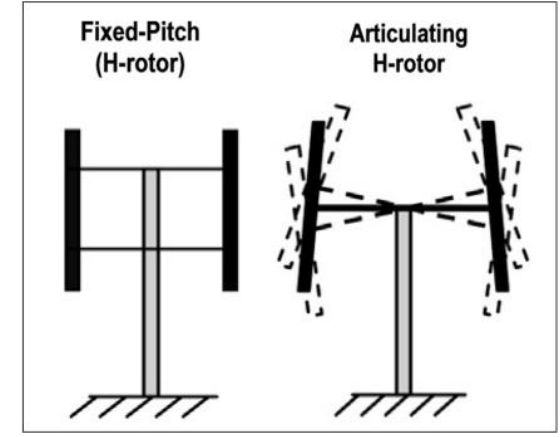

(a)

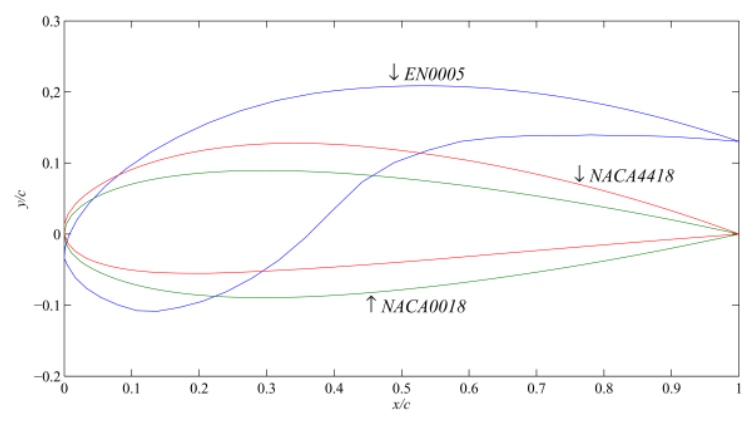

(b)

Gambar 1. (a). Perkembangan Rotor Turbin H-Darrieus 5) (b). Bentuk Profil Airfoil Straight Blade Simetris dan Tidak Simetris

Sumber: Tjiu, dkk, 2015 dan Batista, dkk, 2015

\section{METODE}

Metode pengujian turbin hidrokinetik Articulating H-Rotor dilakukan secara eksperimental untuk mengetahui kemampuan self-starting dan kinerja turbin pada variasi kemiringan sudut straight blade tertentu. Variasi kemiringan straight blade $(\phi)$ diujikan pada sudut $0^{\circ}, 30^{\circ}$ dan $-30^{\circ}$. Turbin hidrokinetik Articulating H-Rotor menggunakan 3 blade dengan airfoil simetris NACA0018. Kriteria Desain Turbin Hidrokinetik ditunjukkan pada Gambar 2.

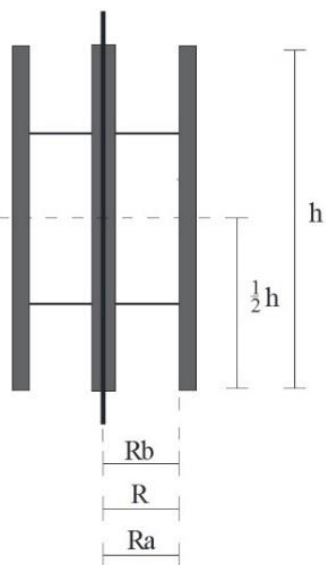

(a)

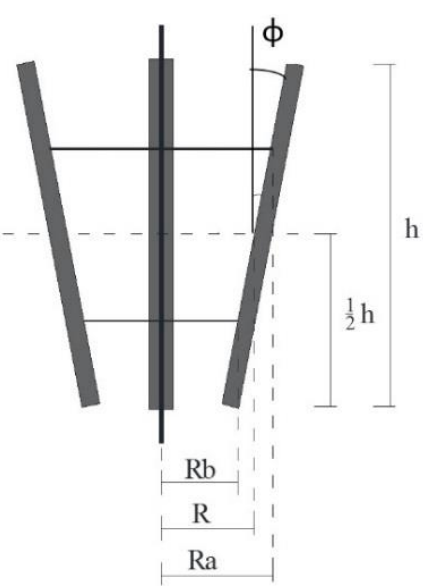

(b)

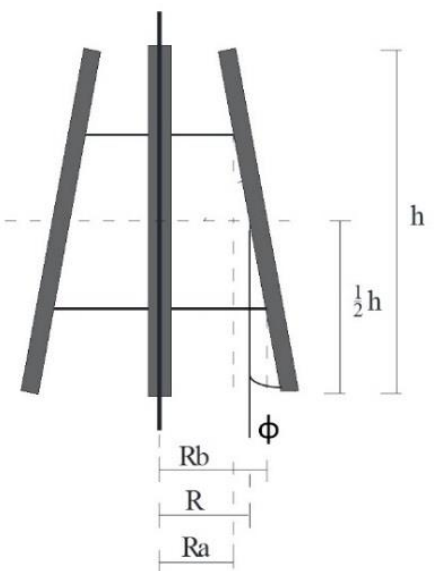

(c)

Gambar 2. Kriteria Desain Turbin Hidrokinetik; (a) Articulating H-Rotor $\phi=0^{\circ}$ (b) Articulating HRotor $\phi=30^{\circ}$ dan (c) Articulating H-Rotor $\phi=-30^{\circ}$

Sumber: Tim Peneliti, 2021

Kriteria desain turbin hidrokinetik Articulating H-Rotor pada uji eksperimental dengan variasi sudut seperti ditunjukkan pada Gambar 2. Jari-jari tengah turbin (R) diukur dari setengah tinggi blade $(1 / 2 \mathrm{~h})$. Turbin hidrokinetik Articulating H-Rotor dengan 3 variasi sudut ini memiliki luas bidang tangkap $\left(\mathrm{A}_{\mathrm{f}}\right)$ yang sama. Parameter dan dimensi Turbin Hidrokinetik Articulating H Rotor tertera pada Tabel 1 . 
Tabel 1. Parameter dan Dimensi Turbin Hidrokinetik Articulating H-Rotor yang Diujikan

\begin{tabular}{lcccc}
\hline \multicolumn{1}{c}{ Parameter } & \multirow{2}{*}{ Satuan } & $\begin{array}{c}\text { Dimensi turbin hidrokinetik Articulating H-Rotor } \\
\phi=0^{\circ}\end{array}$ & $\phi=30^{\circ}$ & $\phi=-30^{\circ}$ \\
\hline Jari-jari turbin & & & & \\
- Atas $(\mathrm{Ra})$ & {$[\mathrm{m}]$} & 0,128 & 0,182 & 0,074 \\
- Tengah $(\mathrm{R})$ & {$[\mathrm{m}]$} & 0,128 & 0,128 & 0,128 \\
- Bawah $(\mathrm{Rb})$ & {$[\mathrm{m}]$} & 0,128 & 0,074 & 0,182 \\
Tinggi lengan blade $(\mathrm{H})$ & {$[\mathrm{m}]$} & 0,32 & 0,37 & 0,37 \\
Chord $(\mathrm{c})$ & {$[\mathrm{m}]$} & 0,013 & 0,013 & 0,013 \\
Tipe airfoil & & NACA0018 & NACA0018 & NACA0018 \\
Luas bidang tangkap $\left(\mathrm{A}_{\mathrm{f}}\right)$ & {$\left[\mathrm{m}^{2}\right]$} & 0,082 & 0,082 & 0,082 \\
Jumlah blade $(\mathrm{n})$ & & 3 & 3 & 3 \\
Soliditas $(\sigma)$ & & 0,3 & 0,3 & 0,3 \\
\hline
\end{tabular}

Sumber: Tim Peneliti, 2021

Tabel 1 menunjukkan parameter turbin hidrokinetik Articulating H-Rotor beserta dimensi yang digunakan. Mekanisme pengujian dilakukan di saluran terbuka berbentuk prismatik melalui uji eksperimental yang merujuk pada studi yang dilakukan Shimokawa, dkk. (2012); Bambang Tutuko, dkk. (2018). Gambar 3 merupakan skema pengujian turbin hidrokinetik Articulating H-Rotor. Gambar 3 (bagian 1) merupakan tandon air yang diisi oleh pompa air dengan variasi debit konstan sehingga elevasi muka air tandon $(\mathrm{Ht})$ tiap percobaan berbeda-beda tingginya. Perbedaan elevasi air di bak penampung (tandon) dengan elevasi muka air di saluran terbuka segi empat (flume) menghasilkan kecepatan aliran (v) di flume yang bervariasi saat melakukan pengujian. Movable weir (bagian 6) berfungsi mengatur elevasi muka air pada saluran flume sehingga aliran yang terjadi adalah steady flow. Gambar 3 (bagian 2) merupakan tempat pengukuran profil distribusi kecepatan aliran menggunakan alat current meter. Gambar 3 (bagian 3) merupakan letak pemasangan turbin di flume. Gaya pada turbin (bagian 4) diukur menggunakan neraca pegas yang selanjutnya digunakan untuk menghitung nilai torsi. Pengukuran Rotasi Per Menit (bagian 5) menggunakan tachometer.

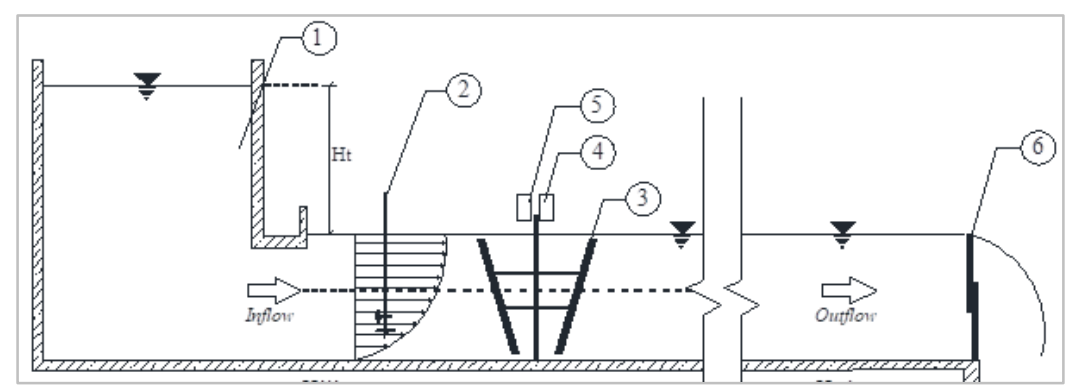

Gambar 3. Skema Uji Eksperimental Turbin Hidrokinetik Articulating H-Rotor di flume Sumber: Tim Peneliti, 2021

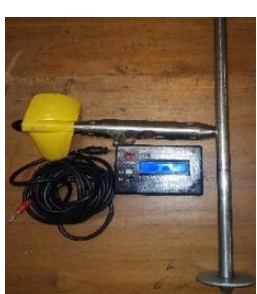

(a)

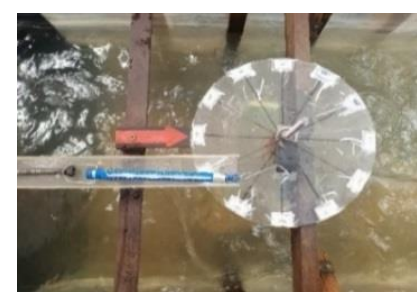

(b)

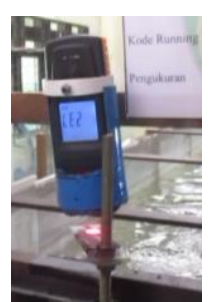

(c)

Gambar 4. Peralatan yang Digunakan (a) Current Meter (SEBA F1519) dan Digital Counter (BBECNT001), (b) Neraca Pegas, (c) Tachometer (GM8905)

Sumber: Tim Peneliti, 2021 


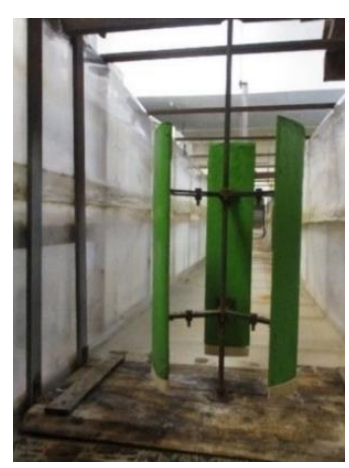

(a)

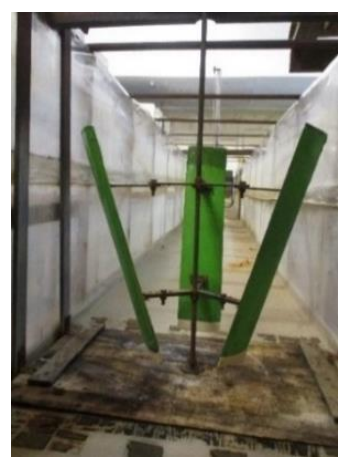

(b)

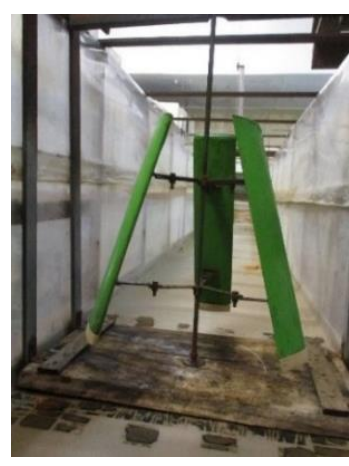

(c)

Gambar 5. Turbin hidrokinetik; (a) Articulating H-Rotor $\phi=0^{\circ}$, (b) Articulating H-Rotor $\phi=30^{\circ}$, dan (c) Articulating H-Rotor $\phi=-30^{\circ}$

Sumber: Tim Peneliti, 2021

Gambar 4 menunjukkan peralatan yang digunakan dalam uji eksperimental dan Gambar 5 menunjukkan perletakan turbin hidrokinetik Articulating H-Rotor menggunakan 3 blade dan 3 variasi kemiringan sudut straight blade. Ukuran flume yang digunakan yaitu lebar $\mathrm{L}_{\mathrm{f}}=0,6 \mathrm{~m}$, tinggi $\mathrm{H}_{\mathrm{f}}=0,6 \mathrm{~m}$ dan kedalaman aliran saat pengujian $\mathrm{H}_{\mathrm{a}}=0,43 \mathrm{~m}$.

Paramater geometri turbin hidrokinetik meliputi soliditas dan Aspek Ratio (AR). Soliditas turbin merupakan parameter utama untuk menentukan geometri turbin sumbu vertikal seperti ditunjukkan pada persamaan (1):

$$
\sigma=\frac{\mathrm{N} . c}{\pi \cdot D}
$$

Berdasarkan persamaan (1), soliditas merupakan perbandingan antara perkalian jumlah bilah (N) dan panjang chord (c) $[\mathrm{m}]$ dengan diameter turbin (D) [m] .

Aspek Rasio rotor Vertical Axis Turbine didefinisikan sebagai rasio antara tinggi blade $(\mathrm{H})[\mathrm{m}]$ dan diameter rotor (D) $[\mathrm{m}]$ seperti pada persamaan (2):

$$
A R=\frac{H}{D}
$$

Nilai Rotasi Per Menit (RPM) terukur dapat digunakan untuk mendapatkan nilai kecepatan sudut $(\omega)[\mathrm{rad} / \mathrm{s}]$ pada turbin, seperti pada persamaan (3):

$$
\omega=\frac{2 \cdot \pi \cdot R P M}{60}
$$

Parameter kinerja turbin ditunjukkan oleh Tip Speed Ratio (TSR) dan nilai Power of Coefficient (Cp). Tip Speed Ratio didefinisikan sebagai rasio antara kecepatan tangensial di ujung bilah turbin dengan kecepatan aliran seperti tertera pada persamaan (4):

$$
T S R=\lambda=\frac{r . \omega}{V}
$$

V adalah kecepatan aliran air [m/s], dan $\mathrm{r}$ adalah jari-jari rotor turbin $[\mathrm{m}]$.

Power of Coefficient $(\mathrm{Cp})$ merupakan perbandingan antara daya turbin dengan daya air menurut persamaan (5):

$$
C_{p}=\frac{P_{\text {turbin }}}{P_{\text {Available }}}=\frac{\tau \omega}{0.5 \rho A V^{3}}
$$

$\mathrm{P}$ adalah daya (watt), $\rho$ adalah massa jenis $\left[\mathrm{kg} / \mathrm{m}^{3}\right], \tau$ adalah torsi $[\mathrm{N} . \mathrm{m}]$ dan A adalah luas bidang tangkap $\left[\mathrm{m}^{2}\right]$. 


\section{HASIL DAN PEMBAHASAN}

Hasil pengukuran kecepatan aliran tiap variasi running percobaan uji ekeperimental disajikan dalam sebuah grafik profil kecepatan aliran seperti yang ditunjukkan pada Gambar 6.

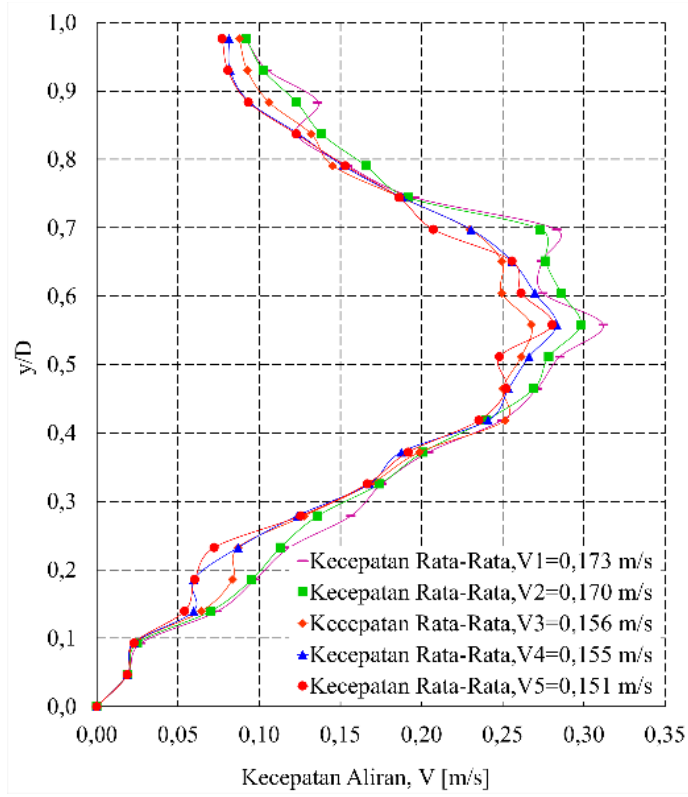

Gambar 6. Distribusi Kecepatan Aliran ketika Pengujian Eksperimental di Saluran Flume

Sumber: Data Primer yang Diolah Tim Peneliti, 2021

Berdasarkan profil distribusi aliran yang ditunjukkan Gambar 6 diperoleh bahwa nilai kecepatan aliran akan mengecil saat mendekati dasar saluran dan meningkat saat mendekati tengah tampang saluran di $(y / D)=0,55$ dimana y adalah titik pengukuran kecepatan dan $\mathrm{D}$ adalah kedalaman aliran. Nilai kecepatan kemudian menurun saat mendekati permukaan aliran. Kecepatan rerata $\left(\mathrm{V}_{1}\right)$ memiliki kecepatan yang tertinggi dan semakin menurun berturut-turut hingga $\mathrm{V}_{5}$. Tabel 2 menunjukkan hasil perhitungan dan perbandingan uji eksperimental berupa nilai torsi, Coefficient of Power, RPM dan Tip Speed Ratio pada 3 variasi sudut straight blade turbin hidrokinetik Articulating HRotor.

Tabel 2. Perbandingan RPM, Coefficient of Power, Torsi dan Tip Speed Ratio Turbin Hidrokinetik Articulating $\mathrm{H}$-Rotor pada kemiringan sudut $0^{\circ}, 30^{\circ}$ dan $-30^{\circ}$

\begin{tabular}{ccccc}
\hline Variasi & Torsi $[\mathrm{Nm}]$ & $\begin{array}{c}\text { Rotasi Per } \\
\text { Menit }\end{array}$ & $C p$ & TSR \\
\hline$\phi=0^{\circ}$ & $0,030-0,049$ & $44,30-50,33$ & $0,067-0,188$ & $3,827-4,226$ \\
$\phi=30^{\circ}$ & $0,038-0,057$ & $41,53-48,20$ & $0,090-0,238$ & $3,693-3,795$ \\
$\phi=-30^{\circ}$ & $0,031-0,052$ & $39,48-45,30$ & $0,072-0,203$ & $3,421-3,649$ \\
\hline
\end{tabular}

Sumber: data primer yang diolah tim peneliti, 2021

Hasil grafik hubungan antara kecepatan aliran dan Rotasi Per Menit (RPM) pada turbin hidrokinetik Articulating H-Rotor ditunjukkan pada Gambar 7a. Berdasarkan grafik hubungan antara kecepatan aliran (V) dan Rotasi Per Menit tersebut terlihat bahwa nilai RPM turbin hidrokinetik Articulating H-Rotor semakin tinggi dengan meningkatnya kecepatan aliran. Nilai RPM turbin hidrokinetik Articulating H-Rotor saat $\phi=0^{\circ}$ lebih besar dibandingkan turbin hidrokinetik Articulating H-Rotor $\phi=30^{\circ}$ dan $\phi=-30^{\circ}$. Desain turbin hidrokinetik Articulating H-Rotor dengan kemiringan straight blade $\left(\phi=0^{\circ}\right)$ memiliki pengaruh gaya lift yang lebih tinggi. 


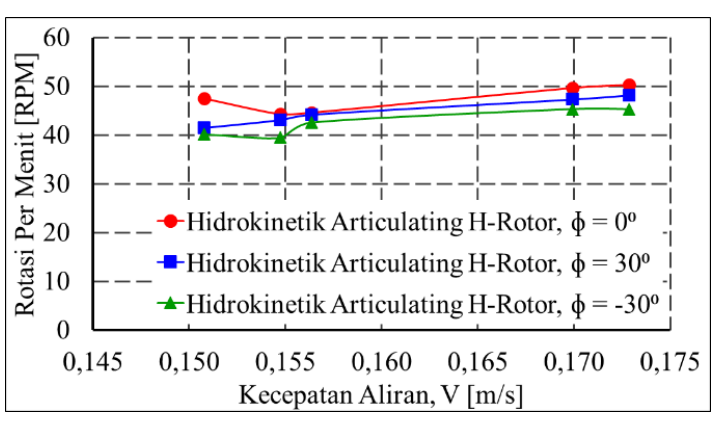

(a)

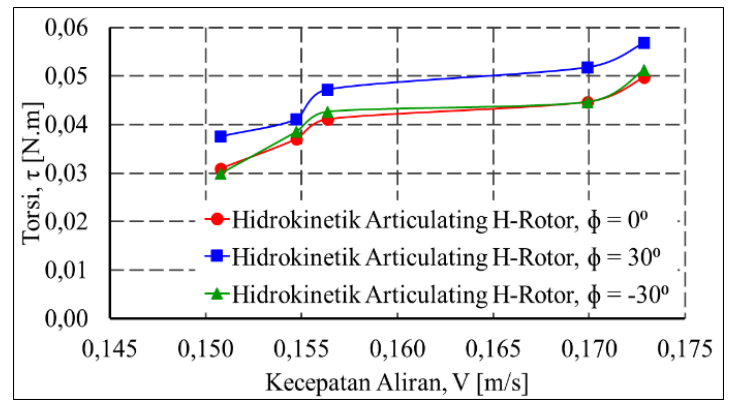

(b)

Gambar 7. Hubungan Antara Kecepatan Aliran dengan (a) Rotasi Per Menit (RPM) (b)Torsi Sumber: data primer yang diolah tim peneliti, 2021

Gambar $7 \mathrm{~b}$ merupakan grafik hubungan kecepatan aliran (V) dengan torsi pada turbin hidrokinetik Articulating H-Rotor. Berdasarkan grafik hubungan kecepatan aliran (V) dengan torsi tersebut menunjukkan bahwa meningkatnya kecepatan aliran menyebabkan nilai torsi semakin besar. Nilai torsi saat straight blade miring sebesar $30^{\circ}$ lebih besar (lebih meningkat) dibandingkan saat straight blade turbin hidrokinetik Articulating H-Rotor dimiringkan $-30^{\circ}$ dan $0^{\circ}$. Hal ini menunjukkan bahwa turbin hidrokinetik Articulating H-Rotor dengan $\phi=30^{\circ}$ menghasilkan gaya drag yang lebih besar sehingga self-starting pada turbin akan meningkat untuk melakukan rotasi. Hasil uji eksperimental hubungan antara nilai torsi di tiap sudut azimuth bisa dilihat pada Gambar 8.

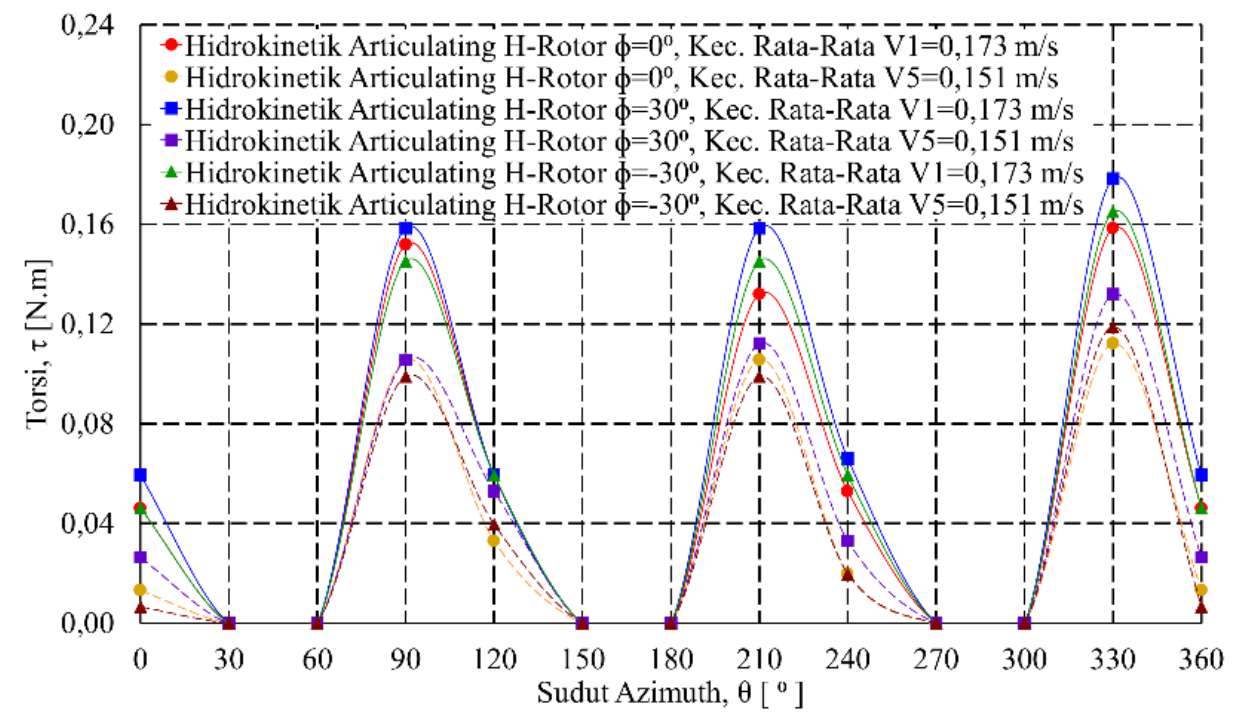

Gambar 8. Hubungan Torsi $(\tau)$ di Setiap Sudut Azimuth $(\theta)$ pada Berbagai Kecepatan (V) Sumber: Data Primer yang Diolah Tim Peneliti, 2021

Berdasarkan Gambar 8 yang merupakan grafik hubungan antara torsi $(\tau)$ turbin pada tiap sudut azimuth $(\theta)$ akibat perubahan kecepatan aliran saat uji eksperimen menunjukkan bahwa nilai torsi meningkat seiring dengan meningkatnya kecepatan aliran pada turbin hidrokinetik Articulating $\mathrm{H}$ Rotor. Pada hasil pengukuran torsi di sudut pengukuran $0^{\circ}, 120^{\circ}$ dan $140^{\circ}$ mengalami penurunan nilai torsi, karena posisi straight blade berada sejajar dengan arah aliran. Pada sudut $90^{\circ}, 210^{\circ}$ dan $330^{\circ}$ nilai torsi meningkat karena posisi straight blade tidak sejajar dengan arah aliran, sehingga membentuk sudut serang yang tepat untuk berotasi. Pada pola grafik terlihat bahwa turbin hidrokinetik Articulating H-Rotor saat straight blade dimiringkan $\phi=30^{\circ}$ menunjukkan peningkatan torsi yang lebih tinggi dibandingkan saat blade turbin hidrokinetik Articulating H-Rotor dimiringkan $\phi=0^{\circ}$ dan $\phi=-30^{\circ}$. 
Kecepatan aliran dapat mempengaruhi nilai torsi pada turbin hidrokinetik Articulating $\mathrm{H}$ Rotor. Gambar 9 merupakan grafik torsi yang terjadi di tiap sudut rotasi turbin. Grafik torsi yang dihasilkan ini memiliki 3 lobes rosette sesuai dengan jumlah bilah yang digunakan pada turbin.

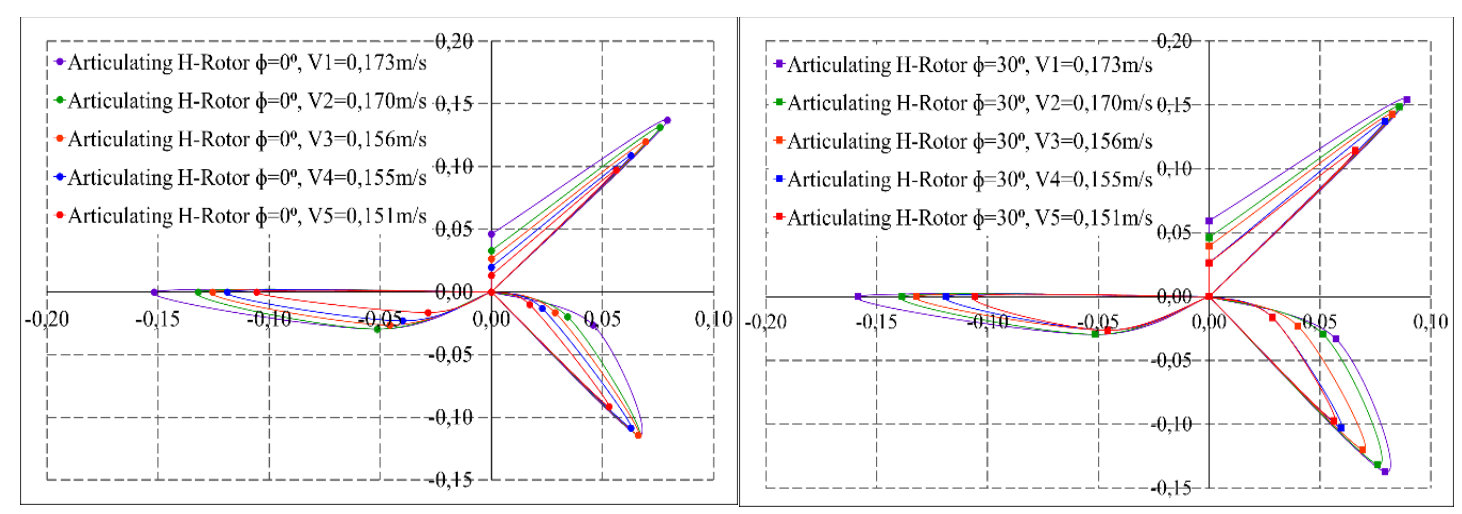

(a)

(b)

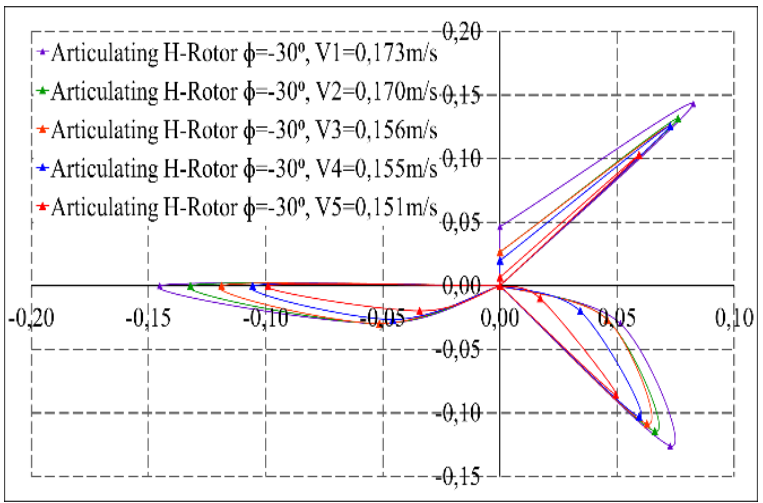

(c)

Gambar 9. Grafik Torsi dengan 3 Lobes Rosette: (a) Turbin Articulating H-Rotor $\phi=0^{\circ}$, (b) Turbin Articulating H-Rotor $\phi=30^{\circ}$ dan (c) Turbin Articulating H-Rotor $\phi=-30^{\circ}$

Sumber: Data Primer yang Diolah Tim Peneliti, 2021

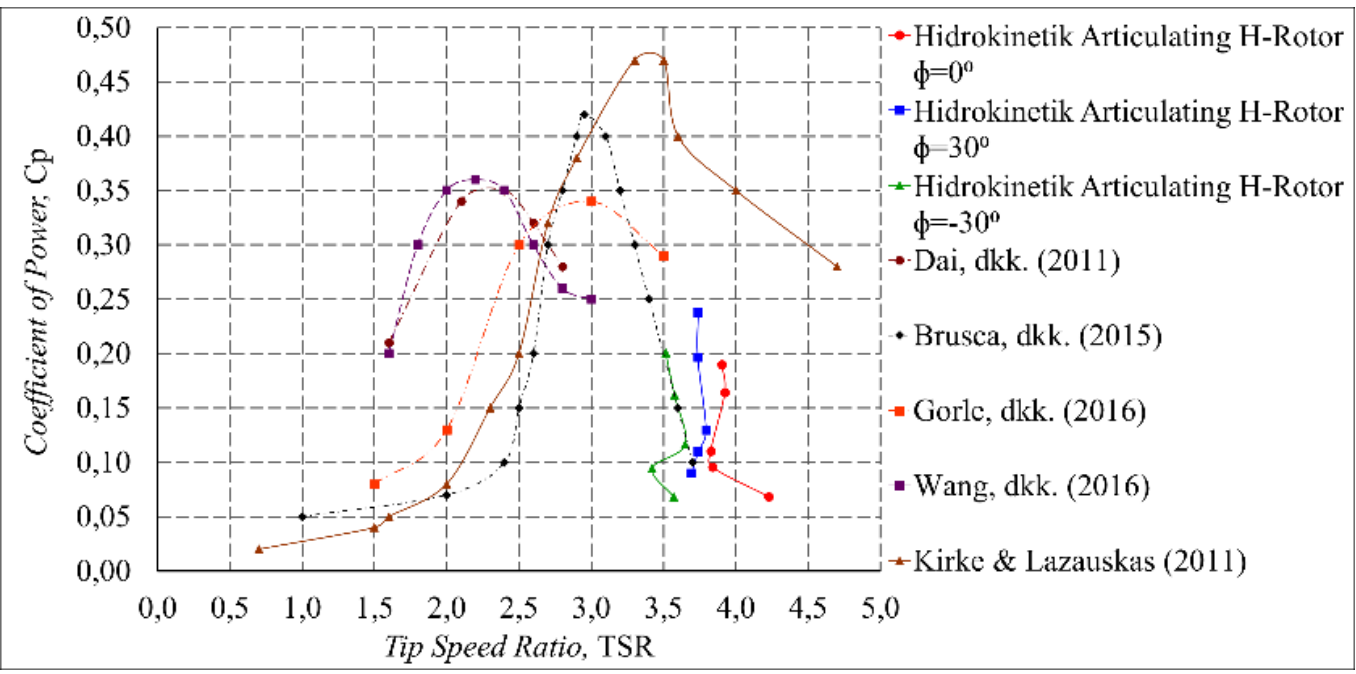

Gambar 10. Hasil Perbandingan Nilai Cp dan TSR Turbin Hidrokinetik Articulating H-Rotor dengan Turbin Hidrokinetik Studi Sebelumnya

Sumber: Data Primer yang Diolah Tim Peneliti, 2021 
Berdasarkan persamaan 3 dan persamaan 4 dapat diketahui bahwa perubahan kecepatan aliran dan RPM mempengaruhi hasil Tip Speed Ratio (TSR). Grafik hubungan TSR dan Cp yang terjadi pada 3 variasi sudut straight blade pada turbin hidrokinetik Articulating H-Rotor jika dibandingkan dengan studi sebelumnya ditunjukkan pada Gambar 10. Berdasarkan grafik TSR dan Cp menunjukkan bahwa turbin hidrokinetik Articulating H-Rotor $\phi=0^{\circ}$ memiliki nilai Tip Speed Ratio (TSR) yang lebih besar dari pada saat straight blade turbin hidrokinetik Articulating H-Rotor dimiringkan $\phi=30^{\circ}$, namun memiliki perolehan Coefficient of Power (Cp) dengan hasil yang lebih kecil. Selisih $\mathrm{Cp}$ yang dihasilkan turbin hidrokinetik Articulating H-Rotor saat kemiringan straight blade $\phi=0^{\circ}$ dan $\phi=30^{\circ}$ sebesar 26,39\% dan TSR menurun sebesar 4,22\%. Turbin hidrokinetik Articulating H-Rotor dengan kemiringan blade $\phi=-30^{\circ}$ menghasilkan $\mathrm{Cp}$ yang yang lebih besar dari pada turbin Articulating $\mathrm{H}$ Rotor $\phi=0^{\circ}$. Selisih nilai $\mathrm{Cp}$ turbin hidrokinetik Articulating H-Rotor saat $\phi=0^{\circ}$ dan $\phi=-30^{\circ}$ sebesar $7,84 \%$ dan TSR menurun sebesar 9,99\%. Uji eksperimental yang dilakukan dalam studi kali ini menggunakan NACA0018 dengan 3 straight blade turbin dan memvariasikan sudut bilah $\phi=0^{\circ}, 30^{\circ}$, $-30^{\circ}$, menghasilkan $\sigma=0,3$, TSR $=3,421-4,226$ dan $\mathrm{Cp}=0,067-0,238$ saat diujikan pada rentang kecepatan rerata aliran $0,151 \mathrm{~m} / \mathrm{s}-0,173 \mathrm{~m} / \mathrm{s}$. Dibandingkan dengan pengujian yang dilakukan Dai, dkk. (2011), Brusca, dkk. (2015), Gorle, dkk. (2016) dan Wang, dkk. (2016), turbin hidrokinetik Articulating H-Rotor memiliki TSR yang tinggi dan Cp yang rendah pada kecepatan aliran yang rendah. Jika dibandingkan dengan uji eksperimental yang dilakukan Kirke \& Lazauskas (2011), nilai TSR turbin hidrokinetik Articulating H-Rotor hampir mendekati namun menghasilkan nilai Cp yang lebih rendah.

\section{SIMPULAN}

Uji eksperimental turbin hidrokinetik Articulating H-Rotor studi ini dilakukan menggunakan profil simetris NACA0018 dengan 3 straight blade turbin dan variasi kemiringan sebesar $\phi=0^{\circ}, 30^{\circ}$ dan $-30^{\circ}$ sehingga diperoleh kemiringan sudut yang mampu meningkatkan self-starting turbin. Desain turbin hidrokinetik Articulating H-Rotor saat blade $0^{\circ}$ memiliki nilai RPM yang lebih besar sehingga mempengaruhi gaya lift. Bentuk proyeksi turbin hidrokinetik Articulating H-Rotor dengan sudut kemiringan $30^{\circ}$ mampu meningkatkan luas tangkap turbin saat aliran air menerpa badan turbin. Bentuk proyeksinya menyerupai bentuk profil distribusi kecepatan aliran yang dihasilkan saat pengujian. Luas tangkap turbin hidrokinetik Articulating H-Rotor dengan blade dimiringkan $30^{\circ}$ terbukti mampu menangkap aliran distribusi kecepatan yang memiliki bentuk menyerupai bentuk proyeksi luas tangkap turbin. Hal ini menghasilkan torsi yang lebih besar, akibatnya gaya drag yang terjadi pun lebih besar sehingga kemampuan self-starting pada turbin menjadi meningkat saat melakukan rotasi. Berdasarkan berbagai variabel pengujian yang telah dilakukan, turbin hidrokinetik Articulating H-Rotor dengan sudut $30^{\circ}$ menghasilkan performa yang paling baik.

\section{DAFTAR PUSTAKA}

Antomo, T., Kamiana, I. M., \& Nindito, D. A. (2020). Analisis Pengembangan Hidrokinetik Turbin Gorlov Akibat Penambahan Luas Bidang Tangkap. Teknika: Jurnal Sains Dan Teknologi, 16(2), 159-170

Arab, A., Javadi, M., Anbarsooz, M., \& Moghiman, M. (2017). A Numerical Study on the Aerodynamic Performance and the Self-Starting Characteristics of a Darrieus Wind Turbine Considering its Moment of Inertia. Renewable Energy, 107, 1-29

Asr, M. T., Nezhad, E. Z., Mustapha, F., \& Wiriadidjaja, S. (2016). Study on Start-Up Characteristics of HDarrieus Vertical Axis Wind Turbines Comprising NACA 4-Digit Series Blade Airfoils. Energy, 112, 528537

Bambang Tutuko, Diah Setyati Budiningrum, (2018). Kajian Aspek Teknis Kapasitas Tampung Sistem Drainase Perumahan Tlogosari Kota Semarang, TEKNIKA, Vol 13. No. 1 10.26623/teknika.v13i1.1865

Batista, N. C., Melício, R., Mendes, V. M. F., Calderón, M., \& Ramiro, A. (2015). On a Self-Start Darrieus Wind 
Turbine: Blade Design and Field Tests. Renewable and Sustainable Energy Reviews, 52, 508-522

Bianchini, A., Ferrari, L., \& Magnani, S. (2016). Start-Up Behavior of a Three-Bladed H-Darrieus VAWT: Experimental and Numerical Analysis. Proceedings of the ASME Turbo Expo (2011) 1811-820, 1, 1-10

Bruce, E. B., Riversong, D., \& Eagle. (2010). Vertical Axis Wind Turbine with Articulating H-Rotor. No. US 7,677,862 B2

Brusca, S., Cucinotta, F., Galvagno, A., Lanzafame, R., Mauro, S., \& Messina, M. (2015). Oscillating Water Column Wave Energy Converter by means of straight-bladed Darrieus turbine. Energy Procedia, 82, 766 773

Dai, Y. M., Gardiner, N., Sutton, R., \& Dyson, P. K. (2011). Hydrodynamic Analysis Models for the Design of Darrieus-Type Vertical-Axis Marine Current Turbines. Proceedings of the Institution of Mechanical Engineers Part M: Journal of Engineering for the Maritime Environment, 225(3), 295-307

Ed-Dîn Fertahi, S., Bouhal, T., Rajad, O., Kousksou, T., Arid, A., El Rhafiki, T., Jamil, A., \& Benbassou, A. (2018). CFD Performance Enhancement of a Low Cut-in Speed Current Vertical Tidal Turbine Through the Nested Hybridization of Savonius and Darrieus. Energy Conversion and Management, 169(February), 266278

Edy Susilo, Bambang Sudarmanto, Bambang Purnijanto (2017). Kajian Empiris Sumur Resapan Pada Tanah Silt, TEKNIKA, Vol. XII No. 2, Oktober 2017: 1-4

Erinofiardi, Gokhale, P., Date, A., Akbarzadeh, A., Bismantolo, P., Suryono, A. F., Mainil, A. K., \& Nuramal, A. (2017). A Review on Micro Hydropower in Indonesia. Energy Procedia, 110(December 2016), 316-321

Gorle, J. M. R., Chatellier, L., Pons, F., \& Ba, M. (2016). Flow and Performance Analysis of H-Darrieus Hydroturbine in a Confined Flow: A Computational and Experimental Study. Journal of Fluids and Structures, 66, 382-402

Ichsan, N., Nindito, D. A., \& Saputra, R. H. (2021). Uji Eksperimental Pengaruh Dimensi Lebar Rectifier Guide Vanes terhadap Kinerja Turbin Hidrokinetik Savonius. RekaRacana: Jurnal Teknik Sipil, 7(2), 96-106

Khan, M. J., Bhuyan, G., Iqbal, M. T., \& Quaicoe, J. E. (2009). Hydrokinetic Energy Conversion Systems and Assessment of Horizontal and Vertical Axis Turbines for River and Tidal Applications: A Technology Status Review. Applied Energy, 86(10), 1823-1835

Kirke, B. K., \& Lazauskas, L. (2011). Limitations of Fixed Pitch Darrieus Hydrokinetic Turbines and the Challenge of Variable Pitch. Renewable Energy, 36(3), 893-897

Nakashima, K., Watanabe, S., Matsushita, D., Tsuda, S., \& Furukawa, A. (2016). Performance Prediction of Darrieus-Type Hydroturbine with Inlet Nozzle Operated in Open Water Channels. IOP Conference Series: Earth and Environmental Science, $49(10), 1-10$

Nindito, D.A, Istiarto, \& Kironoto, B. (2008). Simulasi Numeris Tiga Dimensi Kantong Lumpur Bendung Sapon. Civil Engineering Forum, XVIII/1, 712-724.

Nindito, D.A, \& Kamiana, I. M. (2010). Perencanaan Model PLTA Skala Kecil Berbasis Teknologi Lokal di Daerah Pemukimam Tepi Sungai. Jurnal PROTEKSI, 2(2), 1-7

Octauria, E. P., Nindito, D. A., \& Saputra, R. H. (2021). Uji Eksperimental Pengaruh Sudut Omni Directional Guide Vanes Terhadap Performa Turbin Hidrokinetik Darrieus. EKSERGI Jurnal Teknik Energi, 17(2), 95108

Patel, V., Eldho, T. I., \& Prabhu, S. V. (2017). Experimental Investigations on Darrieus Straight Blade Turbine for Tidal Current Application and Parametric Optimization for Hydro Farm Arrangement. In International Journal of Marine Energy (Vol. 17). Elsevier Ltd

Pratama, A., Nindito, D. A., \& Saputra, R. H. (2021). Studi Eksperimental Sistem Pengarah Aliran Pada Turbin Hidrokinetik Archimedes Spiral. Jurnal Teknik, 19(1), 1-11

Scungio, M., Arpino, F., Focanti, V., Profili, M., \& Rotondi, M. (2016). Wind Tunnel Testing of Scaled Models of a Newly Developed Darrieus-Style Vertical Axis Wind Turbine with Auxiliary Straight Blades. Energy Conversion and Management, 130, 60-70

Shimokawa, K., Furukawa, A., Okuma, K., Matsushita, D., \& Watanabe, S. (2012). Experimental Study on Simplification of Darrieus-Type Hydro Turbine with Inlet Nozzle for Extra-Low Head Hydropower Utilization. Renewable Energy, 41, 376-382

Tanier-Gesner, F., Stillinger, C., Bond, A., Egan, P., \& Perry, J. (2014). Design, Build and Testing of a Hydrokinetic H-Darrieus Turbine for Developing Countries. IEEE Power and Energy Society General Meeting, 2014-Octob(October), 1-5 
Tjiu, W., Marnoto, T., Mat, S., \& Ha, M. (2015). Darrieus Vertical Axis Wind Turbine for Power Generation I : Assessment of Darrieus VAWT Configurations. Renewable Energy, 75, 50-67

Wang, Y., Sun, X. J., Zhu, B., Zhang, H. J., \& Huang, D. G. (2016). Effect of Blade Vortex Interaction on Performance of Darrieus-Type Cross Flow Marine Current Turbine. Renewable Energy, 86, 316-323

Wardani, C. S., Nindito, D. A., \& Jaya, A. R. (2020). Inovasi dan Desain Turbin Hidrokinetik Darrieus Berdasarkan Bentuk Distribusi Kecepatan Aliran. Media Ilmiah Teknik Sipil, 9(1), 32-43

Worasinchai, S., Ingram, G. L., \& Dominy, R. G. (2016). The Physics of H-Darrieus Turbine Starting Behavior. Engineering for Gas Turbines and Power, 138(June 2016), 1-11

Yohanes Sandy Setiadi, Wisnu Suharto, Diah setiati B, (2014). Perhitungan Volume Kolam Retensi Muktiharjo Kidul Semarang Berdasarkan Data Curah Hujan Harian Maksimum Kawasan Kali Tenggang, Jurnal TEKNIKA, Vol. 9 No.2

Yudistira, R., Nindito, D. A., \& Saputra, R. H. (2021a). Kinerja Turbin Hidrokinetik Tornado Savonius. Jurnal Teknika: Jurnal Teoritis Dan Terapan Bidang Keteknikan, 4(2), 181-186

Yudistira, R., Nindito, D. A., \& Saputra, R. H. (2021b). Uji Eksperimental Pengembangan Turbin Hidrokinetik Savonius Berdasarkan Bentuk Profil Distribusi Kecepatan Aliran. RekaRacana: Jurnal Teknik Sipil, 7(1), 111 